\title{
Introduction: The Chiarella-Flaschel Project and its Supporters
}

\author{
Encomium to The Bielefeld and The Ancona Schools: A Way \\ Forward in Macroeconomics?
}

(...) two current schools of macroeconomic thought that I see as offering a wise way forward, the Bielefeld School and the related Ancona School. (...) While the former school is somewhat more aggregated-oriented and the latter is more 'bottom-up' agent-based oriented, (...) both schools emphasize modeling nonlinear interactions between financial and real output markets.

The Bielefeld School is somewhat older, with most of its members being based elsewhere, but with much of the work in terms of numerous books and papers being done while those people have visited Bielefeld, where Peter Flaschel has been permanently based. Chiarella's main base is the University of TechnologySydney while Franke was at the University of Bielefeld/Kiel. Some others who have coauthored with this group include Willi Semmler who is halftime at Bielefeld and the New School (where mentor Duncan Foley is located), Toichiro Asada of Chuo University in Japan, Peter Skott of the University of Massachusetts-Amherst (who provides a link to more conventional Post Keynesians such as Phil Arestis), and Rajiv Sethi himself, who was a grad student at Bielefeld for two years and has coauthored with Flaschel and Franke, among some others. I add to this post now that there is a younger generation meanwhile engaged in part of their writings with this Bielefeld School, such as the 4 co-authors of this book in particular.

The key figure in the Ancona School is Mauro Gallegati, with all the authors of the above-mentioned book being his former grad students (I think) except for longtime coauthor Delli Gatti who is at Milan with Pasinetti, with both of them having worked with Minsky shortly before his death. Gallegati co-founded with Alan Kirman the Workshop on Economic Heterogeneous Interacting Agents (WEHIA, also known as ESHIA), which now has its own journal, the Journal of Economic Interaction and Coordination. Besides his co-founding role, Gallegati's home base in Ancona deserves the moniker for this school as the conferences of WEHIA for the first several of its years of existence took place there at the Universita di Politecnica de Marche, where Gallegati is based. He and Kirman and some others edited volumes of proceedings from 
those conferences, most of them published by Springer. Again, while these two schools have some differences in their approaches, I see them as closely related in methodology and general views, and some combination of the two looks to me to provide as good a view of what is going on now as we have, as well as a promising way forward in terms of research and understanding.

(...) Again, while these two schools have some differences in their approaches, I see them as closely related in methodology and general views, and some combination of the two looks to me to provide as good a view of what is going on now as we have, as well as a promising way forward in terms of research and understanding.

(John Barkley Rosser Jr., James Madison University, shortened and slightly updated version of the original post: http://econospeak.blogspot.de/2009/ 11/encomium-to-bielefeld-and-ancona.html)

The very fruitful scientific collaboration between myself $(\mathrm{PF})$ and my very close friend and supporter, the late Carl Chiarella (CF), began in 1993, during my stay as visiting professor at the University of Technology in Sydney in a three month lovely autumn (their spring), which completely changed my research interests and agenda and, I believe, also widened his perspective as far as his earlier contributions to nonlinear dynamic macroeconomics were concerned. The big initial step of our collaboration (after some joint papers) was our first book publication The Dynamics of Keynesian Monetary Growth: Macro-Foundations at Cambridge University Press in 2000, the intellectual basis for all of our subsequent work on small, medium and large scale Keynesian macro-dynamic model building in closed as well as open economies. Over the years thereafter we had the luck to attract the interest of a variety of younger and very talented and also well trained researchers in this area of rigorous model building and complex numerical simulations (see e.g. The SND Package: Applications to Keynesian Monetary Growth Dynamics with A. Khomin and P. Zhu). In the 'older' generation we; in particular, attracted the interest of Reiner Franke who elevated our approach, the KMG (Keynes-Metzler-Goodwin) macro-dynamics, to a new level through his detailed further theoretical and numerical analyses.

The present book would possibly have been finished in a different way if Carl would had lived long enough to participate in its final completion. Somewhat different views, of course, may also have been chosen by the younger co-authors of this book, who may have expressed various things differently. In order not to mix up things of the original approach by CF, I am grateful to them that we could stick to the original $\mathrm{CF}$ perspective by and large, regrettably reduced to $\mathrm{F}$ in the MKS-part of the book. Needless to say, the whole book is open to any critical alternative attempt to model unbalanced growth. This will, in particular, hold for the rigorously working colleagues closer to the Post-Keynesian school of heterodox economics and their focus on Kalecki and Minsky, authors who are surely doing research complementary to our work, meanwhile extended towards the analysis of a Goodwin-oriented Marx-Keynes-Schumpeter (MKS) system, which in this integrated form is - in principle - based on six fundamental dynamic variables as shown in the final chapter 11 of part II. 
The book resulted directly or indirectly as well as many other joint publications, from the 10 visits of mine to Sydney (in sum nearly two years) and numerous visits of Carl to Bielefeld, as well as from the many conferences we jointly visited in Europe and elsewhere. Chapters 3, 4, 6, 7, 10 and 11 as a whole were already published by refereed journals (with copyright references given in the first endnotes of each chapter). Chapters 6 and 10 are based on invited papers, in order to make these parts - oriented towards the history of unorthodox and rigorous economic thought of this book - sufficiently comprehensive. Three chapters (5, 9, 12) moreover exhibit also an external collaborator, not represented by the Bielefeld School. This book jointly written with Ricardo, Matthieu, Christian and Andreas as the younger collaborators in this project, summarizes our work in a somewhat final form. It presents and extends earlier contributions which, through their rigorous macro-dynamic modelling approaches, had a significant impact on supporters of our research agenda.Last, but not least, we - and especially I - have to thank Uwe Koeller for his great and relaxing support in getting this book into this final form, by his enormous help in checking and formatting it according to the guidelines provided by the wonderful staff of the publisher Edward Elgar. He is in this way also a member of the Bielefeld School, since he gave this support already for a variety of other books of the School. He also studied in Bielefeld, but had to leave it after his exam to the North Frisian Island of Amrum on the German North Sea coast into a climate supportive to his health - and also into a social climate of peaceful rest, in particular in the current times of COVID-19.

Regarding our three patron saints Marx, Keynes and Schumpeter, one has to understand the neoclassical literature on macro-economics sufficiently good if one really wants to understand and synthesise their original contributions. This is all the more true when we see them as the founders of (in modern terms) a System of National Accounts in terms of labor values (and the productivity growth cycle as ruthless conflict between capital and labor derived on this basis), the principle of effective demand and its interaction with monetary theory, and of the socio-economic waves of capitalism, respectively. In this context it does not make much sense in forming competing Post-, Neo-, New-Keynesian, etc. peer-groups or schools (with their wage-led bias, rigid regime-switching methodology, or Walrasian tâtonnement background), not to speak of the type of Marxism that followed the great analytical contributions of Gérard Duménil and Dominique Lévy, Duncan Foley and others, on the one hand, and of John Roemer and others, on the other hand, with a lot of further ramifications in between.

Schumpeter is the presumably strange component in Goodwin's MKS system from the perspective of the Post-Keynesian school, often including Schumpeter's more Marx-oriented scholar Goodwin himself as an alien to heterodox thinking. The latter's M-contribution was completely ignored by even such prominent economists like Joan Robinson, when she declared that the observed 'stagflation' in the 1970s was a completely new phenomenon in the history of the cyclical growth of capitalism. This is somewhat peculiar, as it was Goodwin who first formalized the Marxian Reserve Army Mechanism 100 years after the appearance of Marx's Capital I (where a profit-squeeze and its consequences 
is a central part of the dynamics). But the rigorous understanding of Marx's Capital was not very common for verbally oriented economists in Cambridge at that time (a subject where empirically-oriented input-output analysts like Nobel Laureate Wassily Leontief, Andras Bródy and Cambridge's Nobel Laureate Richard Stone - and Richard Goodwin - were much more open to). Schumpeter is only on the surface the exotic 'component' in the MKS system, since he is the only socially oriented economist who could be digested by the 'Neoclassicals'. He basically defined innovation as a change in the 'production function' of the economy. This idea was then formalized by the mainstream economists through endogenous growth theory, neglecting, however all his further insights into often spontaneous socio-economic changes in capitalist economies. In particular, they largely ignored his thesis that capitalism itself will ultimately fail, not due to its inherent Marxian contradictions, but in fact due to its success.

These views are not necessarily the ones of our younger co-authors - and of my late friend Carl, where regarding the former Carl and I are highly indebted for making the balanced perspective of this book possible and finalizing it as our heritage (despite this possibly unbalanced preface of mine, due to my dislike of dogmatism of any kind). Nevertheless both camps (whether orthodox or heterodox) exhibit significant exceptions (which I had the pleasure to experience during my scientific life), who - as researchers - in various ways personalize(d) Marx's remark to Engels: 'Si c'est cela le marxisme, il est certain que moi, Karl Marx, je ne suis pas marxiste.'

From today's perspective it looks, however, in view of the intended integrated mathematical analysis of the theories of Marx, Keynes and Schumpeter that unleashed Capitalism will destroy the planet (through its contradictions - M or its success S) and that Socialism will lock all basic innovations (the good ones, the bad ones should already be a matter of current public policy), so that solely some sort of Social Capitalism can rescue the world from either MStype system catastrophes and the consequence of K-type casino capitalism - or socially-vested administrative despotism.

This book is dedicated to Carl, who much too early passed away in 2016, after a life of intensive fruitful research in finance and economics. My collaborators and I can only deeply regret his recent passing away. I personally keep his wife Lyn in very good remembrance, the many excellent dinners and talks we had together, and the great support she gave to Carl in the difficult days he had to face at the end of his life.

Peter Flaschel

Bielefeld, September 30, 2019 (*1943, same day)

Financial support (one year with no teaching obligation, allowing me in particular my visit as invited Theodor-Heuss Professor at the New School for Social Research in New York City) is gratefully acknowledged by PF for the Opus Magnum Research Grant: 'Beyond the Mainstream' received from the Fritz Thyssen/Volkswagen Foundation in Hanover for the research of this now finished book of a grown Bielefeld School. I sent my final report to the 
Foundation with a number of related books that temporarily dominated our research by the occurrence of the second world-wide financial crisis and the then already pressing question of the future of capitalism, currently put on the scientific agenda once again through the Coronavirus-induced third world-wide, now socio-economic crisis and the 'spread of facade democracies' (Habermas, 2012, 'Der Standard'). I did not yet finalize, however, the initially intended project (for which I apologize), which meanwhile led me, and my coauthors in particular, into the analytical foundations for Goodwin's MKS system (a system which includes an unorthodox mainstream economist!), starting as it was initially scheduled from a history of prominent unorthodox research on unbalanced growth, meanwhile leading us to a much richer understanding of capitalism in this final book of the Bielefeld School (as far as I am concerned), than it was suggested by me when the project was started. But the results achieved in my view clearly show a way 'Beyond the mainstream' that may be urgently needed as 'vision' for the future of capitalism, in a theory of 'Social Capitalism' in place of its current ruthless form, too much supported by mainstream economics in the past.

Earlier further financial support for my first visit to the UTS came from the German Research Foundation which is also gratefully acknowledged here. 
schel, Reiner Franke, Ricardo Araujo, Matthieu Charpe, Christian R. Proaño, and Andreas Szczutkowski - 9781789908008 Downloaded from PubFactory at 04/26/2023 02:40:15PM via free access 